\title{
Multifunctional Express Delivery Truck
}

\author{
Niu Liu \\ No. 2 Beinong Road, Huilongguan Town, Changping District, Beijing, North China Electric \\ Power University
}

297974540@qq.com

Keywords: Express delivery truck; Multifunctional; Lift; Climbing; Foldable

\begin{abstract}
With the rapid development of e-commerce, more and more people choose to ship online. Meanwhile, the logistics industry is also booming and express delivery has already become an indispensable part of people's life. Thus, how to reduce the work intensity of the courier and improve their work efficiency has become a problem. Traditional express delivery vehicles have relatively single function, so the delivery process is also more difficult. Therefore, we improve and innovate traditional express delivery vehicles, and the improved vehicles can not only reduce the workload of couriers, but also have other functions: the table of express delivery truck can be lifted and fixed at any height, and the carrier vehicle can be folded and easy to carry with the triangle wheel climbing stairs, so more efforts can be saved in the delivery process.
\end{abstract}

\section{Contents of the Work}

This work is designed according to the requirements of the current mechanical creative design contest theme, it can help the courier carrying and moving goods and so on, so it can not only reduce delivery staff labor intensity but also guarantee the product safety mechanism. Our works belong to "carriage-assisting machinery". The multifunctional express handling bicycle structure is mainly composed of a screw rod nut, roller chute mechanism, fork lift mechanism, a universal wheel, sleeve, and climb stairs triangle wheel etc. mechanism. The main frame of this work is metal aluminum and aluminum rod.

We design the multifunctional express delivery truck to solve the problem of delivering goods from the truck to the designated place. It is a multifunctional folding express delivery truck. The height of the table can be adjusted, and when the truck arrives at the designated site, this car will be boosted to start, adjusting the height of the table to reach the same height of the truck, you can easily push the goods to the transport vehicles. After the goods are transported to the carrier, the first two are closed up into a climbing car, and the courier can pull the goods to the designated location, which is time-saving and convenient.

The functions that can be achieved mainly include:

Life height can be adjusted so the carrier can more conveniently carry goods to this delivery truck;

This carrier can be folded into 180 degrees, so the carrier can pull it away, saving more efforts;

The two wheels in front of it are triangle wheels, which can improve the stability and add the function of climbing stairs;

The two wheels behind are universal wheels, so it is more convenient for carriers to push this car.

\section{Project Background}

With the rapid development of the logistics industry, express delivery has become an indispensable part of people's daily life. The courier uploads goods from the car at the designated site, and then carries them to each household in batch. How to reduce the workload of the courier and improve the efficiency of the courier's work has become a very important issue. However, as the majority of the express delivery vehicles are relatively simple, the courier often feels very difficult in the process of carrying goods. On the other hand, the general delivery vehicles can only be pushed to the ground 
without the function of the stairs, so if you want to move the goods to the top, it cannot be achieved with traditional carrier.

We all know that in the process of delivering goods, the courier usually first moves down goods of the express company from the truck, sort them, and then deliver them. The countertops of our multifunctional delivery truck can be lifted to the same height of the truck, and then we can directly push the goods from the truck to our vehicles, which is labor-saving and quick. Therefore, we make improvement and innovation based on the traditional delivery truck, and the novel multifunctional express delivery trick not only has all the functions of traditional vehicles, but also has new functions, reducing working strength of the courier and improving their work efficiency.

\section{Outline Diagram}

The Solidworks simulation of our multifunctional delivery truck at three work conditions is as follows:
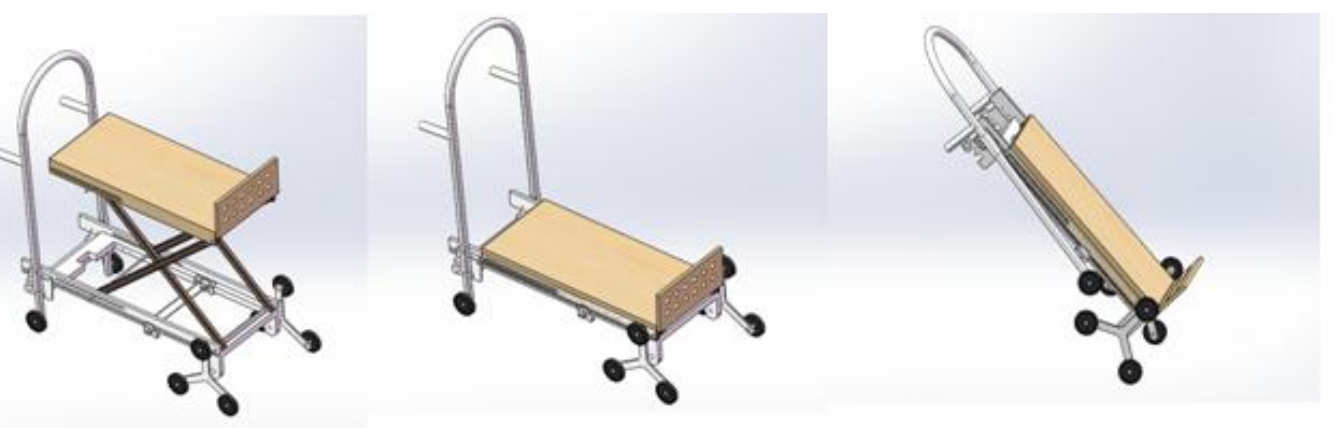

Figure 1. Expanding and Folding Diagram of the Truck

\section{Design Scheme}

Overall Design. In order to reduce the weight, we use the structure of the metal frame. The whole car is supported by four large wheels: two front smaller diameter casters and two rear triangle is capable of climbing stairs round. There are two whole device mesa, a fixed four-wheeled chassis, and a removable can adjust the height of the work surface. In terms of the lifting height work platform,we use a pulley connected to the fork mechanism and set the slide in the chute to achieve the purpose of lifting.

\section{Overall Framework.}

Chassis. In order to reduce body weight and save materials, we use a hollow metallic frame as the material of the chassis framework, and in order to load and unload the lift table and folding handrail, we leave a groove and rolling bearing on the chassis.

The overall chassis 3D diagram is as follows:

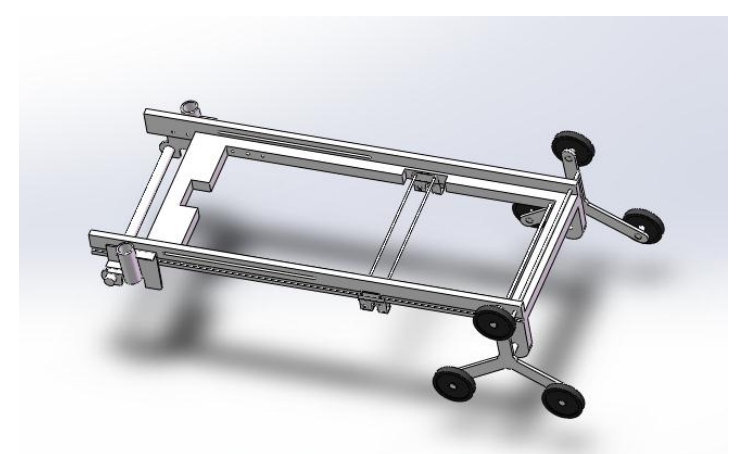

Figure 2. Design Diagram of 3D Chassis 
Enlarged image of the rolling bearing is as follows:

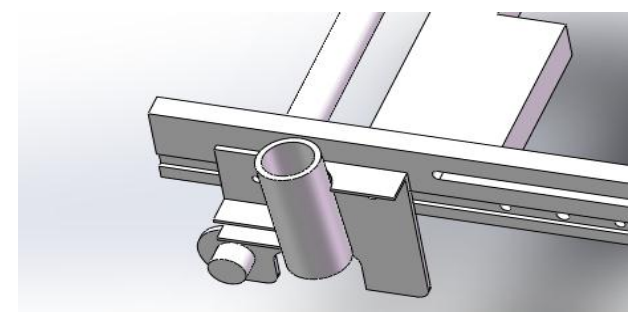

Figure 3. 3D Design Diagram of Rolling Bearing

We install a baffle in front of the rolling bearing and its connected cylinder so that the rolling bearing and cylinder can rotate to 90 degrees, and the cylinder can stably push the vehicle after handrails are installed.

Handrails. We use the hollow aluminum material as parts of the handrail, the bending of the circular tube and rotating bearing is connected to the cylinder can be realized folding function, and two universal wheels and arm round the bottom of the tube is connected.

$3 \mathrm{D}$ design diagram of the handrail is as follows:

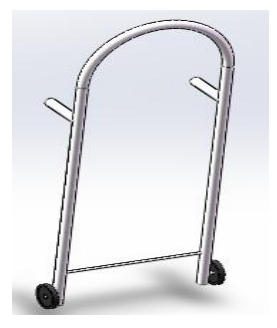

Figure 4. 3D design diagram of the handrail

Listing Work Platform. In order to reduce the weight and for beautiful appearance, we use pine as the material of the lifting work table, table are fixed by stainless steel tubes and lifting device, the bottom of the table leave $200 \mathrm{~mm}$ long slot, in table lifting pulley in the rolling.

$3 \mathrm{D}$ design diagram of the work platform is as follows:

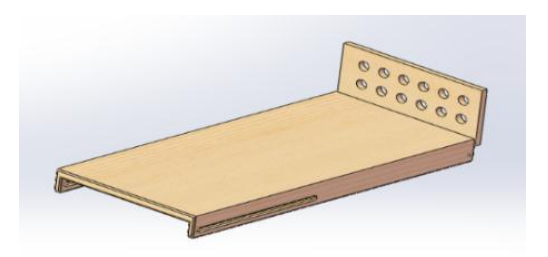

Figure 5. 3D Design Diagram of the Lifting Platform

\section{Adjust Height of the Lifting Platform}

Fork Lifting Device. We use the fork lifting device to carry the goods on the truck. The lifting platform can rise to the same height of the bottom of the truck to easily push the goods into the car. Fork lifting device of the movable pulley are respectively arranged in the groove of the chassis and lifting platform, when the rotary lifting handle, fork lifting device of the movable pulley slides in the groove in order to change height of the lifting platform.

Fixing Screwing Rod Device. Although only using the fork lifting machine can adjust the height, it cannot fix the work platform at a certain height, so we need to use the screw rod to fix the work platform on a height.

We use the Solidworks to simulate the 3D structure of the screw rod as follows: 


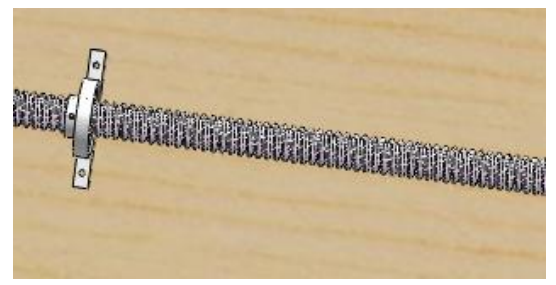

Figure 6. 3D Design Diagram of Screw Rod

Folding Self-Locking Device. In order to make the structure more stable from the truck after the establishment of the wagon folding type motorcycle, we have designed a folding self-locking device, and the three-dimensional design is as follows:

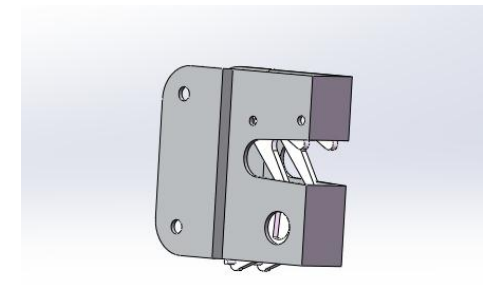

Figure 7. 3D Design Diagram of Folding Self-Locking Device

Folding self-locking mechanism with two metal aluminum rod is connected and fixed on the chassis of the vehicle, we in parts of the handrail design of aluminum rod can promote grooves in the self-locking device, to push can be aluminum rod parts of the handrail of the lock, so that when in the carriage of the folded becomes more stable.

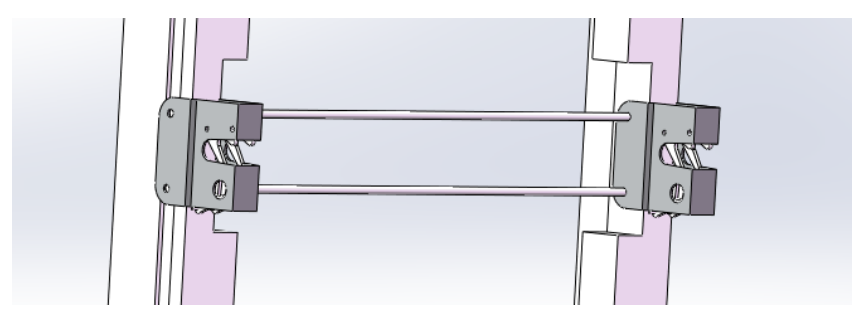

Figure 8. Connection of Folding Self-Locking Device and Chassis

\section{Promotion Application Value}

With the rapid development of e-commerce, more and more people choose to shop online, and the daily express is ever increasing, so it is necessary to have a multifunctional and practical carrier to meet the demand of ever increasing deliveries and reduce the workload if couriers on the market.

In addition, carrier vehicle is also a universal device widely used in daily life, not only in the express delivery industry, but also in many other places, so our multifunctional express delivery truck has great potential on the market, and we can vigorously promote it.

\section{References}

[1] Zhou Fengyu, Lv Ding. Mechanical Design Foundation [M]. Beijing: Mechanical Industry Press 
[2] Zhou Zhaohua, Chen Zhenhua. Fork Lift-Platform Design [J]. Mechanical Manufacturing, 2010,01

[3] Liu Weixin, Optimal Mechanical Design [M]. Beijing: Qinghua University Press, 1994-09

[4] Miu Dongsheng, Chen Min, Liu Xiaoqiu, Research and Application of a New Type of Rolling Screw Rod [J]. New Technology and New Technique, 2009,04

[5] Pu Nianggui, Ji Minggang, Mechanical Design (the 8th version) [M]. Beijing: High Education Press.

[6] Liu Huiying, Yang Zhiqiang, Zhang Mingqin, Mechanical Principles [M] Beijing: Mechanical Industry Press.

[7] Luo Yingshe, Materials Mechanics [M] Wuhan: Wuhan University of Technology Press

[8] Huang Wenhu, Tan Jianrong, Mechanical Design Manual [M] Beijing: Mechanical Industry Press

[9] Shen Menghong, Influence of Screw's Stiffness on Load Distribution of Screw Rod [J] Mechanical Design and Manufacturing, 1993, 05

[10]Chen Yuqing, Improvement and Application of Scissor Fork Life Table [J] Chemical Engineering and Equipment, 2008, 10 